\title{
Role of RNA-binding protein 5 in the diagnosis and chemotherapeutic response of lung cancer (Review)
}

\author{
YANLING XU ${ }^{1,2}$, ZHENZHONG SU$^{1}$, JUNYAO LI ${ }^{1}$, QI WANG ${ }^{1}$, GUANGPING MENG ${ }^{1}$, \\ $\mathrm{YU} \mathrm{ZHANG}^{2}$, WEN YANG ${ }^{2}$, JIE ZHANG ${ }^{1}$ and PENG GAO ${ }^{1}$ \\ Departments of ${ }^{1}$ Respiratory Medicine, and ${ }^{2}$ Geriatrics and General Medicine, \\ The Second Affiliated Hospital of Jilin University, Changchun, Jilin 130041, P.R. China
}

Received March 7, 2018; Accepted October 4, 2018

DOI: $10.3892 / \mathrm{ol} .2018 .9818$

\begin{abstract}
Lung cancer remains one of the leading causes of cancer-associated mortality in the world. Lung carcinogenesis is frequently associated with deletions or the loss of heterozygosity at the critical chromosomal region 3p21.3, where RNA-binding protein 5 (RBM5) is localized. RBM5 regulates cell growth, cell cycle progression and apoptosis in cell homeostasis. In the lungs, altered RBM5 protein expression leads to alterations in cell growth and apoptosis, with subsequent lung pathogenesis and varied responses to treatment in patients with lung cancer. Detection of RBM5 expression may be a tumor marker for diagnosis, prediction and treatment response in lung cancer, and may be developed as a potential therapeutic target for drug resistant lung cancer. This review discusses the most recent progress on the role of RBM5 in lung cancer.
\end{abstract}

\section{Contents}

1. Introduction

2. Functions of RBM5 in human cells

3. Tobacco use and deletion of the RBM5 locus

4. Altered RBM5 expression in human cancer types

5. Targeting RBM5 as a therapeutic strategy for lung cancer

6. Conclusions

\section{Introduction}

Lung cancer is one of the most common cancer types and one of the leading causes of cancer-associated mortality worldwide.

Correspondence to: Dr Jie Zhang or Dr Peng Gao, Department of Respiratory Medicine, The Second Affiliated Hospital of Jilin University, 218 Ziqiang Street, Nanguan, Changchun, Jilin 130041, P.R. China

E-mail: doctorzhangj@sina.com

E-mail: gaopeng1234@sina.com

Key words: RNA-binding motif 5, lung cancer, biomarker, molecular target therapy
In 2012, lung cancer accounted for $\sim 13 \%$ of all cancer cases and $26 \%$ of cancer-associated mortality, according to recent data (1). In China alone, there were 733,000 new lung cancer cases diagnosed in 2011 (17\% of all new cancer cases), and 600,200 lung cancer-associated mortalities (22\% of all cancer-associated mortalities) (2). Histologically, lung cancer is classified as small cell lung cancer (SCLC) and non-small cell lung cancer (NSCLC), the latter of which accounts for up to $85 \%$ of all lung cancer cases (3). NSCLC may be further sub-categorized as adenocarcinoma, squamous cell carcinoma, large cell carcinoma and numerous other less common types of cancer, including pleomorphic, carcinoid tumor or undifferentiated carcinoma; however, lung adenocarcinoma makes up $44 \%$ and lung squamous cell carcinoma makes up $29 \%$ of all NSCLC cases clinically. At present, $79 \%$ of NSCLC patients are diagnosed at advanced stages of the disease, when surgery is not a viable option (4). Thus, early detection, optimal tumor resection and effective chemotherapy, radiotherapy, immunotherapy and tumor-targeting therapy are important for the effective control of NSCLC. Therefore, a better understanding of NSCLC carcinogenesis and the underlying molecular mechanisms is key to developing novel early diagnosis strategies and improving treatment responses for NSCLC.

Lung carcinogenesis, like most human cancer types, is a complex molecular process involving aberrant cell proliferation (5) and apoptosis (6), which leads to the transformation of normal cells into malignant cells and subsequent cell invasion and metastasis. Cell transformation occurs through genetic mutations, loss of cell growth/critical genes, or epigenetic alterations in genomic DNA that silence tumor suppressor genes or activate oncogenes (7), resulting in abnormal cell-cell communication (8), DNA repair (9), chromosome stability (10) and cell motility $(6,11)$. Recently, NSCLC was reported to exhibit abnormal expression of epidermal growth factor receptor (EGFR) (12-14), c-Met (15), thyroid transcription factor 1 (TTF-1) (16), phosphoinositide 3-kinase/Rac- $\alpha$ serine/threonine-protein kinase/serine-threonine-protein kinase mTOR signaling (17), Ras-Raf-Mek-extracellular signal-regulated kinase signaling $(18,19)$ and the echinoderm microtubule associated protein like 4-ALK receptor tyrosine kinase fusion gene $(20,21)$. In addition, NSCLC may present with alterations in tumor suppressor genes, including RB transcriptional corepressor 1 (RB), p16-RB (16) and 
p14-MDM2 proto-oncogene-cellular tumor antigen p53 (p53) signaling (22), and other regulatory molecules, including microRNAs (23) or angiogenesis factors such as vascular endothelial growth factor (24). However, despite marked progress in understanding the molecular basis of human tumorigenesis, including lung cancer, a number of crucial genes and functions remain undefined. For example, RNA-binding protein 5 (RBM5) is localized at chromosome 3p21.3, a critical region associated with lung carcinogenesis. RBM5 regulates cell growth, cell cycle progression and apoptosis. Aberrant RBM5 protein expression leads to the transformation of normal bronchial cells, lung carcinogenesis, and alters the response of patients with lung cancer to treatment (24). In this review, the role of RBM5 in lung cancer is summarized.

\section{Function of RBM5 in human cells}

RBM5, also referred to as g15, LUCA-15 and H37, was initially cloned from a tumor suppressor gene (TSG) mapping area at chromosome 3p21.3 (25). RBM5 cDNA contains a full-length 815 -amino acid open reading frame, with a predicted protein weight of $\sim 90 \mathrm{kDa}(25)$. The RBM5 protein has two zinc finger motifs, two RNA binding motifs and a bipartite nuclear signal. RBM5 localizes to the cell nucleus where it processes transcribed RNA, due to its DNA/RNA binding function (26). Earlier studies reported that the N-terminal of human RBM5 contains an RNA binding domain and RBM5 epitope marker (27), and that it had a priority function involving the poly $(\mathrm{G})$ RNA polymer in vitro (28). At the C-terminal, RBM5 contains multiple regions, including a rich glutamine domain and a specific site for RNA and DNA binding proteins (28). RBM5 is widely expressed in various human tissues, particularly during embryonic development and in the adult thymus, although it is expressed at low levels in the fetal thymus (27) and normal lung (28). Another study reported a series of splice variants in RBM5 (29). In a normal lung, expression levels of the short transcript of RBM5 are higher compared with lung cancer cell lines, suggesting that the short RBM5 transcript may contribute to its tumor suppressor function in lung cancer (28).

Biologically, RBM5 facilitates DNA/RNA binding to process transcribed RNA, and regulates cell cycle progression and apoptosis during sperm maturation, bone and cardiac cell differentiation (30-32). Specifically, RBM5 may modulate the alternative splicing of apoptosis-associated pre-mRNAs, including caspase 2 (CASP2) and Fas cell surface death receptor (FAS/CD95), to regulate cellular apoptosis $(33,34)$. RBM5 may also upregulate the pro-apoptotic apoptosis regulator BAX protein, reduce mitochondrial cytochrome $c$ release into the cytosol and activate caspase 9 and 3, whilst also downregulating the anti-apoptotic apoptosis regulator BCL-2 (BCL-2) and BCL-2 like 1 proteins $(30,35,36)$ [Fig. 1; modified from (37)]. These data suggest that RBM5 may be able to activate the mitochondrial apoptosis pathway. Indeed, RBM5 is able to manipulate the pre-mRNA splicing of multiple target genes, including p53 (30,35,36,38-42). Kobayashi et al (43) reported that RBM5 expression enhanced p53 mRNA expression levels and protein expression, whereas knockdown of RBM5 using RBM5 short hairpin RNA inhibited p53 transcription and protein expression, indicating that RBM5 regulates p53-mediated cell apoptosis. Furthermore, RBM5 is able to regulate apoptosis and cell cycle progression by increasing signal transducer and activator of transcription $5 \mathrm{~B}$ and bone morphogenetic protein 5 expression levels, and reducing nuclear receptor coactivator 3 , Pim-1 proto-oncogene serine/threonine kinase, baculoviral IAP repeat containing 3, BCL-2, EGFR and cyclin dependent kinase 2 expression levels (44-47). In addition, RBM5 was demonstrated to inhibit cyclin A expression and RB phosphorylation, and thereby regulate cell cycle progression and induce G1 arrest (30). Although initially cloned from a TSG-mapping area at chromosome 3p21.3, RBM5 was previously dismissed as a TSG due to the lack of RBM5 mutations and its expression in the majority of lung cancers. Furthermore, there are multiple RBM5 protein isoforms, each of which differentially regulates apoptosis, leading to its inconsistent role as a tumor suppressor gene (48); however, a previous study did confirm its tumor suppressor function in lung cancer and other cancer types (49).

In eukaryotic cells, gene expression is almost completely regulated through mRNA splicing, and selective mRNA splicing ensures the diversity of functional proteins in cells (50). Thus, the accuracy and effectiveness of mRNA splicing are essential for maintaining homeostasis in eukaryotic cells. Defects in mRNA splicing are associated with various human diseases (2,51-53). In this regard, RBM5 is involved in the selective mRNA splicing of apoptosis and cell cycle-associated genes (see above). For example, Fushimi et al (34) demonstrated that RBM5 regulated CASP2 splicing and expression in order to promote tumor suppression, whereas alternative splicing of CASP2 led to a loss of tumor suppressor activity. Thus, modulation of mRNA splicing regulators, like RBM5, may provide a novel therapeutic strategy to control human cancer. Bonnal et al (33) demonstrated that RBM5 was involved in recognizing the mRNA 3'-splice site in order to regulate the alternative splicing of apoptosis-associated mRNAs and their isoforms (including Fas receptor) in angiogenesis and apoptosis. RBM5 is unable to influence the early events of mRNA splicing for FAS at exon 6; however, RBM5 is able to inhibit the transition from the pre-spliceosome around FAS exon 6 into the mature spliceosome between the flanking FAS introns to induce DNA sequence-specific pairing in the distal mRNA splicing site. Jin et al (54) reported that RBM5 overexpression significantly induced exon 4 skipping of activation-induced cytidine deaminase by suppressing intron 3 splicing. This inhibitory effect required a weak mRNA 3'-splice site. As a result, RBM5 is able interfere with the binding of splicing factor U2AF $65 \mathrm{kDa}$ subunit to polypyrimidines at the mRNA 3 '-splice site in vitro (50). Taken together, the selective functions and alterations of RBM5 may alter the cell cycle and apoptosis, resulting in human tumorigenesis.

\section{Tobacco use and deletion of the RBM5 locus}

Tobacco use is the primary risk factor for developing human lung cancer (55). A number of previous studies have demonstrated that tobacco use contributes to cancer development, including lung, esophageal, bladder, pancreatic and kidney cancer (55). Tobacco contains at least 2,550 known chemical compounds and $>60$ of these have been demonstrated to be carcinogenic in humans and experimental animals (56). Polycyclic aromatic hydrocarbons (PAHs), including benzo(a) 


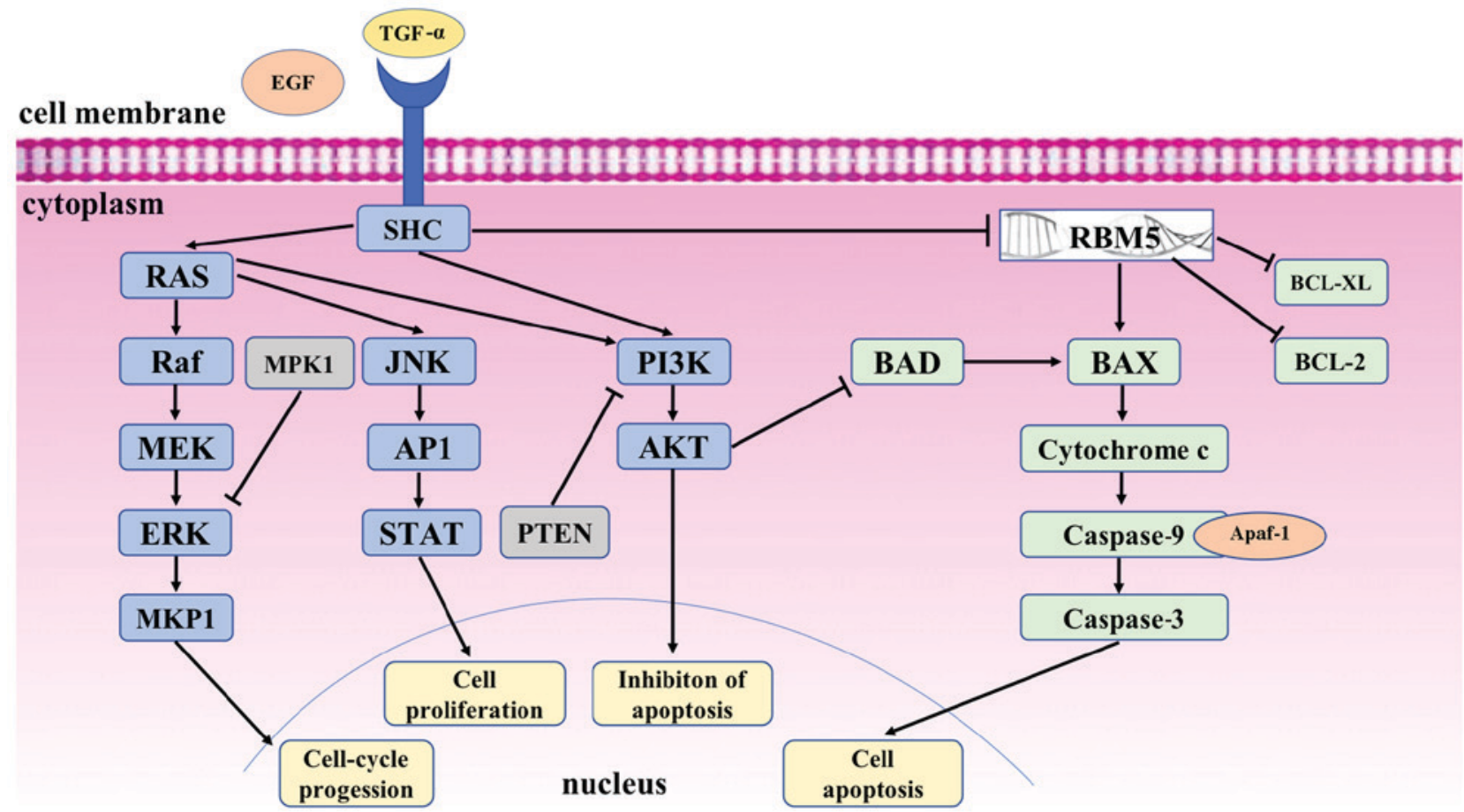

Figure 1. TGF and RBM5 signaling cascade. The left hand side of the image illustrates cell growth pathways. Mutations in EGFR, HER2, or KRAS result in enhanced tumor cell growth and reduced apoptosis. Mutant RAS (G12V) results in RBM5 expression and cell survival. Likewise, increased EGFR and HER2 activation lead to phosphorylation and subsequent inhibition of the apoptotic activity of BAD. The right hand side of the image illustrates the apoptosis pathway. RBM5 overexpression is associated with BCL-XL downregulation and BAX upregulation, which induces cytochrome $c$ release from the mitochondria and activates caspase-9 and caspase-3. Antisense RBM5 transfection leads to BCL-2 expression. TGF, transforming growth factor; RBM5, RNA-binding protein 5; EGFR, epidermal growth factor receptor; HER2, human epidermal growth factor receptor 2; BAD, BCL2 associated agonist of cell death; PI3K, phosphoinositide 3-kinase; BCL-2, apoptosis regulator BCL-2; ERK, extracellular signal-regulated kinase; MKP1, mitogen activated protein kinase phosphatase 1; SHC, SHC adaptor protein; STAT, signal transducer and activator of transcription; KRAS, KRAS proto-oncogene GTPase; AP1, activator protein 1; JNK, c-Jun N-terminal kinase; AKT, RAC- $\alpha$ serine/threonine-protein kinase; PTEN, phosphatase and tensin homolog; BAX, apoptosis regulator BAX; BCL-XL, BCL-2-like 1; Apaf-1, apoptotic protease activating factor-1.

pyrene diol epoxide (BPDE) and N-nitrosamines, are the most highly carcinogenic compounds in tobacco $(56,57)$. PAHs induce DNA adducts, genetic mutations, methylation and chromosome translocation in target organs $(58,59)$. For example, BPDE reacts with cellular macromolecules to form DNA adducts, which are carcinogen metabolites covalently bound to DNA (58-60) that induce apoptosis (61). Alternatively, if permanent mutations occur in a critical region of a DNA coding gene, an oncogene may be activated or a tumor suppressor gene deactivated, leading to aberrant cell growth, migration, adhesion and, ultimately, cancer (60). Previous studies that have reported direct evidence of tobacco carcinogen-targeted genes, including hot spot mutations in the KRAS proto-oncogene GTPase (KRAS) and p53 genes $(60,62)$.

Furthermore, previous studies demonstrated that allele loss in a $370 \mathrm{~kb}$ region at chromosome 3p21.3 was the earliest alteration detected in pre-malignant lesions of lung cancer, or even in the histologically normal lung epithelium of tobacco smokers (63). Thus, Timmer et al (25) performed a comparative genomic structure and expression pattern analysis of this chromosomal region and identified RBM5. Specifically, RBM5 was involved in EGFR downregulation to prevent lung cancer cell proliferation, angiogenesis, invasion and metastasis $(64,65)$.

One potential EGFR binding partner, the proto-oncoprotein human epidermal growth factor receptor 2 (HER2)/ErbB2, was reported to be overactive in a small percentage of patients with
SCLC and non-smoker-associated NSCLC cases $(66,67)$. These activating mutations of EGFR, KRAS and HER2 are mutually exclusive events in lung cancer $(68,69)$. Notably, HER2 overexpression affects the alternative splicing of RBM5 (48). In light of these advances in lung cancer research, it may be speculated that future studies on RBM5 and its potential tumor suppressor activity should consider histological subtypes as well as tobacco smoking history and the mutation status of RBM5 in lung cancer initiation and/or progression. A previous in vitro study reported that RBM5 downregulation and activation of the Wnt/ $\beta$-catenin signaling pathway are involved in cigarette smoke extract-induced lung epithelial injury, and that RBM5 functions as an upstream molecule to downregulate Wnt/ $\beta$-catenin signaling (70). Interestingly, RBM5 knockout mice develop lung cancer at similar rates compared with those in wild type mice following exposure to nicotine-derived nitrosamine ketone. Loss of RBM5 expression leads to more aggressive lung cancer. Thus, reduced RBM5 expression and tobacco use increase the risk of an aggressive lung cancer phenotype (64).

\section{Altered RBM5 expression in human cancer types}

Lung cancer pathogenesis is multifactorial and results from the interaction between genetic and environmental factors. At the molecular level, genetic alterations are the most direct causes of lung cancer, and lung cancer development is associated with the deletion of tumor suppressor gene loci, including 
3 p21.3 $(52,26)$, which may be observed in $>90 \%$ of SCLC and in 50-80\% of NSCLC cases (71). RBM5 expression levels are low in Ras-transformed rat embryonic fibroblasts (72), human vestibular schwannoma cells (73), human prostate cancer (74), ovarian cancer $(74,75)$, human breast cancer tissue (48), human pancreatic cancer tissues (76) and lung cancer (77). Overexpression of RBM5 suppresses the growth of prostate cancer cells in vitro $(74,75)$, and RBM5 expression is associated with lung cancer histological subtypes and tobacco use (78).

Although RBM5 expression is frequently reduced in lung, renal and breast cancer (79), RBM5 is not deleted in the majority of lung cancer cases (80). The reduced levels of RBM5 mRNA and protein in NSCLC compared with levels in normal lung tissues are associated with increased EGFR and KRAS expression levels, which are associated with tobacco use, advanced tumor stage and lymph node metastasis (81). Another study reported that RBM5 expression levels were significantly reduced in lung squamous cell tissues and were further associated with deletions at chromosome $3 \mathrm{p} 21.3$ and tobacco use $(71,78)$, whereas three out of nine patients with lung adenocarcinoma did not have significant decreases in RBM5 mRNA expression levels (lung adenocarcinoma development may be associated with tobacco use, among which $50 \%$ of cases are associated with chromosome 3 p21.3 deficiency) (78). Furthermore, Oh et al (82) reported that RBM5 expression was generally lower in lung cancer compared with normal lung tissues. Thus, detection of RBM5 expression may be a useful tumor marker for lung cancer.

RBM5 expression is able to suppress the growth of mouse fibrosarcoma cells or lung adenocarcinoma cells in nude mouse models $(30,82,83)$. Notably, a number of genes were mapped to the common deletion region of chromosome 3p21.3, including RBM5 (25), FUS RNA binding protein (84), Ras association domain family member 1 (85), semaphorin 3B (86), semaphorin $3 \mathrm{~F}(49)$, hyaluronidase 1 (49) and calcium voltage-gated channel auxiliary subunit $\alpha 2 \delta 2$ (87), and had the ability to modulate lung cancer cell apoptosis. Reduced expression levels of RBM5, as one of nine downregulated genes in this 17-gene metastatic signature for solid tumors (including lung cancer) in humans and mice, was considered important for the development and/or progression of a wide range of human cancer types $(88,89)$. Indeed, a recent study demonstrated that downregulation of RBM5 expression levels may be the key step in malignant lung cell transformation, and that RBM5 is responsible for inhibiting cell cycle progression and inducing apoptosis, in addition to suppressing tumor cell transformation-associated events, including angiogenesis, in SCLC cells (90). Furthermore, at the gene level, a constitutively activated RAS mutant protein (G12V) was demonstrated to be responsible for RBM5 downregulation in rat embryonic fibroblasts (72). Therefore, RBM5 may be a tumor marker for SCLC, and targeting RBM5 may be a potential novel and effective therapeutic option for controlling SCLC.

Thus far, the published data indicate that RBM5 is a lung cancer regulatory protein; however, the detection of various RBM5 isoforms may also be used to the determine association between lung cancer histological subtype and tobacco use, or even RBM5 mutation status (40). Moreover, further research on RBM5 alterations associated with other genes in the transforming growth factor signaling pathway is warranted (37). For example, RBM5 was able to post-transcriptionally regulate RBM10 expression by directly interacting with specific RBM10 splice variants (91).

\section{Targeting RBM5 as a therapeutic strategy for lung cancer}

As discussed above, RBM5 mRNA and protein expression levels are significantly reduced in different human cancer types, including lung cancer; thus, targeting RBM5 may be a novel therapeutic strategy for treating lung cancer. Indeed, a previous study revealed that cisplatin-resistant lung adenocarcinoma A549/DDP cells expressed decreased levels of RBM5 compared with parental A549 cells (41). Furthermore, knockdown of RBM5 expression with small interfering RNA in parental A549 cells reduced cisplatin-induced apoptosis. By contrast, exogenous RBM5 expression using a plasmid carrying RBM5 cDNA enhanced the sensitivity of A549/DDP cells to cisplatin treatment (41). In addition, RBM5-enhanced chemosensitivity to cisplatin was associated with cytochrome $c$ release into the cytosol and subsequent activation of CASP9 and CASP3 (38). RBM5 expression inhibits the growth of human lung cancer cells by inducing cell cycle arrest and apoptosis (30). A previous study demonstrated the importance of RBM5 protein expression in normal lung cells and the consequences of RBM5 deletion in SCLC development and progression (90). RBM5 expression slowed the growth of SCLC cells in vitro and increased the sensitivity of tumor cells to cisplatin. Moreover, RBM5 expression inhibited SCLC cell cycle progression and reduced tumor cell membrane integrity (increase in apoptosis) following treatment with cisplatin. In this regard, reduced RBM5 expression was observed in 95\% of SCLC cases, indicating the importance of altered RBM5 expression levels in SCLC development (76). Thus, a therapeutic strategy involving RBM5 and/or its direct target genes or pathways may be a very effective approach. In addition, detection of RBM5 expression might be useful for predicting response to chemotherapy in patients with lung cancer. The mechanism by which RBM5 affects gefitinib resistance in lung adenocarcinoma is currently being investigated (Xu et al, unpublished data).

\section{Conclusions}

Environmental factors, including tobacco use, may interact with human genes to cause cancer development and progression. As indicated in 2000 by Hanahan and Weinberg (6), there are six essential hallmarks of cancer cells: i) Self-sufficiency in growth signals; ii) insensitivity to growth-inhibitory signals; iii) evasion of apoptosis; iv) limitless replicative potential; v) sustained angiogenesis; and vi) tissue invasion and metastasis. RBM5 possesses at least two of these hallmarks. Thus, further investigations into RBM5 alterations, including chromosomal deletion, loss of heterozygosity, DNA methylation and/or gene-gene interactions, may lead to a better understanding of how RBM5 functions in lung cancer, leading to the development of a novel therapeutic strategy for the treatment of lung cancer. Further research on RBM5 may provide a novel mechanism to induce RBM5 expression or activate its downstream gene pathways. Moreover, detection of RBM5 
expression, or its isoforms, may lead to early diagnosis of lung cancer and improve prognosis of patients with lung cancer.

\section{Acknowledgements}

Not applicable.

\section{Funding}

This review was supported in part by a grant from Nature Science Foundation of China (grant no. 81472169).

\section{Availability of data and materials}

Not applicable.

\section{Authors' contributions}

YX and PG participated in writing the original draft and in the design of this review; ZS participated in writing the original draft; JL, QW and GM researched the relevant literature; YZ participated in writing and editing the manuscript; WY managed the references and participated in the design of this review; $\mathrm{JZ}$ participated in the design of the review and in acquiring funding. All authors contributed substantially to the writing of this review. All authors read and approved the final manuscript.

\section{Ethics approval and consent to participate}

Not applicable.

\section{Patient consent for publication}

Not applicable.

\section{Competing interests}

The authors declare that they have no competing interests.

\section{References}

1. Siegel RL, Miller KD and Jemal A: Cancer Statistics, 2017. CA Cancer J Clin 67: 7-30, 2017

2. Chen W, Zheng R, Baade PD, Zhang S, Zeng H, Bray F, Jemal A, $\mathrm{Yu}$ XQ and He J: Cancer statistics in China, 2015. CA Cancer J Clin 66: 115-132, 2016.

3. American Cancer Society, Cancer Facts \& Figures, 2016 Available from: https://www.cancer.org/research/cancer-factsstatistics/all-cancer-facts-figures/cancer-facts-figures-2016.html. Accessed: January 20, 2018.

4. Carrato $\mathrm{A}$, Vergnenègre $\mathrm{A}$, Thomas $\mathrm{M}, \mathrm{McBride} \mathrm{K}$, Medina $\mathrm{J}$ and Cruciani G: Clinical management patterns and treatment outcomes in patients with non-small cell lung cancer (NSCLC) across Europe: EPICLIN-Lung study. Curr Med Res Opin 30: 447-461, 2014.

5. Hunt T and Nasmyth K: Cell multiplication. Curr Opin Cell Biol 9: 765-767, 1997.

6. Mueller BM, Yu YB and Laug WE: Overexpression of plasminogen activator inhibitor 2 in human melanoma cells inhibits spontaneous metastasis in scid/scid mice. Proc Natl Acad Sci USA 92: 205-209, 1995.

7. Hanahan D and Weinberg RA: The hallmarks of cancer. Cell 100: $57-70,2000$.

8. Hirschi KK, Xu CE, Tsukamoto T and Sager R: Gap junction genes $\mathrm{Cx} 26$ and $\mathrm{Cx} 43$ individually suppress the cancer phenotype of human mammary carcinoma cells and restore differentiation potential. Cell Growth Differ 7: 861-870, 1996.
9. Sancar A: DNA repair in humans. Annu Rev Genet 29: 69-105, 1995.

10. Hanawalt PC: Transcription-coupled repair and human disease. Science 266: 1957-1958, 1994.

11. Stetler-Stevenson WG, Aznavoorian S and Liotta LA: Tumor cell interactions with the extracellular matrix during invasion and metastasis. Annu Rev Cell Biol 9: 541-573, 1993.

12. Ichihara S, Toyooka S, Fujiwara Y, Hotta K, Shigematsu H, Tokumo M, Soh J, Asano H, Ichimura K, Aoe K, et al: The impact of epidermal growth factor receptor gene status on gefitinib-treated Japanese patients with non-small-cell lung cancer. Int J Cancer 120: 1239-1247, 2007.

13. Soh J, Okumura N, Lockwood WW, Yamamoto H, Shigematsu H, Zhang W, Chari R, Shames DS, Tang X, MacAulay C, et al: Oncogene mutations, copy number gains and mutant allele specific imbalance (MASI) frequently occur together in tumor cells. PLoS One 4: e7464, 2009.

14. Wei Y, Zou Z, Becker N, Anderson M, Sumpter R, Xiao G, Kinch L, Koduru P, Christudass CS, Veltri RW, et al: EGFR-mediated Beclin 1 phosphorylation in autophagy suppression, tumor progression, and tumor chemoresistance. Cell 154: 1269-1284, 2013.

15. Menges CW, Kadariya Y, Altomare D, Talarchek J, Neumann-Domer E, Wu Y, Xiao GH, Shapiro IM, Kolev VN, Pachter JA, et al: Tumor suppressor alterations cooperate to drive aggressive mesotheliomas with enriched cancer stem cells via a p53-miR-34a-c-Met axis. Cancer Res 74: 1261-1271, 2014.

16. Toyooka S, Mitsudomi T, Soh J, Aokage K, Yamane M, Oto T, Kiura K and Miyoshi S: Molecular oncology of lung cancer. Gen Thorac Cardiovasc Surg 59: 527-537, 2011.

17. Guo Y, Du J and Kwiatkowski DJ: Molecular dissection of AKT activation in lung cancer cell lines. Mol Cancer Res 11: 282-293, 2013.

18. Collisson EA, Trejo CL, Silva JM, Gu S, Korkola JE, Heiser LM, Charles RP, Rabinovich BA, Hann B, Dankort D, et al: A central role for $\mathrm{RAF} \rightarrow \mathrm{MEK} \rightarrow \mathrm{ERK}$ signaling in the genesis of pancreatic ductal adenocarcinoma. Cancer Discov 2: 685-693, 2012.

19. De Luca A, Maiello MR, D'Alessio A, Pergameno $M$ and Normanno N: The RAS/RAF/MEK/ERK and the PI3K/AKT signalling pathways: Role in cancer pathogenesis and implications for therapeutic approaches. Expert Opin Ther Targets 16 (Suppl 2): S17-S27, 2012.

20. Suda K, Tomizawa K, Yatabe Y and Mitsudomi T: Lung cancers unrelated to smoking: Characterized by single oncogene addiction? Int J Clin Oncol 16: 294-305, 2011.

21. Wu SG, Kuo YW, Chang YL, Shih JY, Chen YH, Tsai MF, Yu CJ, Yang CH and Yang PC: EML4-ALK translocation predicts better outcome in lung adenocarcinoma patients with wild-type EGFR. J Thorac Oncol 7: 98-104, 2012.

22. Paci M, Rapicetta $C$ and Maramotti S: New biomarkers for lung cancer. Expert Opin Med Diagn 4: 201-224, 2010.

23. Shen J, Liu Z, Todd NW, Zhang H, Liao J, Yu L, Guarnera MA, Li R, Cai L, Zhan M and Jiang F: Diagnosis of lung cancer in individuals with solitary pulmonary nodules by plasma microRNA biomarkers. BMC Cancer 11: 374, 2011.

24. Claesson-Welsh L: Blood vessels as targets in tumor therapy. Ups J Med Sci 117: 178-186, 2012.

25. Timmer T, Terpstra P, van den Berg A, Veldhuis PM, Ter Elst A, Voutsinas G, Hulsbeek MM, Draaijers TG, Looman MW, Kok K, et al: A comparison of genomic structures and expression patterns of two closely related flanking genes in a critical lung cancer region at 3p21.3. Eur J Hum Genet 7: 478-486, 1999.

26. Daigo Y, Nishiwaki T, Kawasoe T, Tamari M, Tsuchiya E and Nakamura Y: Molecular cloning of a candidate tumor suppressor gene, DLC1, from chromosome 3p21.3. Cancer Res 59: 1966-1972, 1999.

27. Aravind L and Koonin EV: G-patch: A new conserved domain in eukaryotic RNA-processing proteins and type D retroviral polyproteins. Trends Biochem Sci 24: 342-344, 1999.

28. Drabkin HA, West JD, Hotfilder M, Heng YM,Erickson P, Calvo R, Dalmau J, Gemmill RM and Sablitzky F: DEF-3(g16/NY-LU-12), an RNA binding protein from the 3p21.3 homozygous deletion region in SCLC. Oncogene 18: 2589-2597, 1999.

29. Sutherland LC, Rintala-Maki ND, White RD and Morin CD: RNA binding motif (RBM) proteins: A novel family of apoptosis modulators? J Cell Biochem 94: 5-24, 2005.

30. Oh JJ, Razfar A, Delgado I, Reed RA, Malkina A, Boctor B and Slamon DJ: 3p21.3 tumor suppressor gene H37/Luca15/RBM5 inhibits growth of human lung cancer cells through cell cycle arrest and apoptosis. Cancer Res 66: 3419-3427, 2006. 
31. Loiselle JJ and Sutherland LC: Differential downregulation of Rbm5 and Rbm10 during skeletal and cardiac differentiation. In Vitro Cell Dev Biol Anim 50: 331-339, 2014.

32. O'Bryan MK, Clark BJ, McLaughlin EA, D'Sylva RJ, O'Donnell L, Wilce JA, Sutherland J, O'Connor AE, Whittle B, Goodnow CC, et al: RBM5 is a male germ cell splicing factor and is required for spermatid differentiation and male fertility. PLoS Genet 9: e1003628, 2013.

33. Bonnal S, Martinez C, Förch P, Bachi A, Wilm M and Valcárcel J: RBM5/Luca-15/H37 regulates Fas alternative splice site pairing after exon definition. Mol Cell 32: 81-95, 2008.

34. Fushimi K, Ray P, Kar A, Wang L, Sutherland LC and Wu JY: Up-regulation of the proapoptotic caspase 2 splicing isoform by a candidate tumor suppressor, RBM5. Proc Natl Acad Sci USA 105: 15708-15713, 2008.

35. Mourtada-Maarabouni M, Sutherland LC and Williams GT: Candidate tumour suppressor LUCA-15 can regulate multiple apoptotic pathways. Apoptosis 7: 421-432, 2002.

36. Sutherland LC, Lerman M, Williams GT and Miller BA LUCA-15 suppresses CD95-mediated apoptosis in Jurkat T cells. Oncogene 20: 2713-2719, 2001

37. Sutherland LC, Wang K and Robinson AG: RBM5 as a putative tumor suppressor gene for lung cancer. J Thorac Oncol 5: 294-298, 2010.

38. Li P, Wang K, Zhang J, Zhao L, Liang H, Shao C and Sutherland LC: The 3p21.3 tumor suppressor RBM5 resensitizes cisplatin-resistant human non-small cell lung cancer cells to cisplatin. Cancer Epidemiol 36: 481-489, 2012.

39. Mourtada-Maarabouni M, Sutherland LC, Meredith JM and Williams GT: Simultaneous acceleration of the cell cycle and suppression of apoptosis by splice variant delta- 6 of the candidate tumour suppressor LUCA-15/RBM5. Genes Cells 8: 109-119, 2003.

40. Rintala-Maki ND and Sutherland LC: LUCA-15/RBM5, a putative tumour suppressor, enhances multiple receptor-initiated death signals. Apoptosis 9: 475-484, 2004.

41. Sutherland KD, Lindeman GJ, Choong DY, Wittlin S, Brentzell L, Phillips W, Campbell IG and Visvader JE: Differential hypermethylation of SOCS genes in ovarian and breast carcinomas. Oncogene 23: 7726-7733, 2004.

42. Sutherland LC, Edwards SE, Cable HC, Poirier GG, Miller BA, Cooper CS and Williams GT: LUCA-15-encoded sequence variants regulate CD95-mediated apoptosis. Oncogene 19: 3774-3781, 2000.

43. Kobayashi T, Ishida J, Musashi M, Ota S, Yoshida T, Shimizu Y, Chuma M, Kawakami H, Asaka M, Tanaka J, et al: p53 transactivation is involved in the antiproliferative activity of the putative tumor suppressor RBM5. Int J Cancer 128: 304-318, 2011.

44. Mourtada-Maarabouni M, Keen J, Clark J, Cooper CS and Williams GT: Candidate tumor suppressor LUCA-15/RBM5/H37 modulates expression of apoptosis and cell cycle genes. Exp Cell Res 312: 1745-1752, 2006.

45. Shao C, Yang B, Zhao L, Wang S, Zhang J and Wang K: Tumor suppressor gene RBM5 delivered by attenuated Salmonella inhibits lung adenocarcinoma through diverse apoptotic signaling pathways. World J Surg Oncol 11: 123, 2013.

46. Shao C, Zhao L, Wang K, Xu W, Zhang J and Yang B: The tumor suppressor gene RBM5 inhibits lung adenocarcinoma cell growth and induces apoptosis. World J Surg Oncol 10: 160, 2012

47. Su Z, Yin J, Zhao L, Li R, Liang H, Zhang J and Wang K: Lentiviral vector-mediated RBM5 overexpression downregulates EGFR expression in human non-small cell lung cancer cells World J Surg Oncol 12: 367, 2014.

48. Rintala-Maki ND, Goard CA, Langdon CE, Wall VE, Traulsen KE, Morin CD, Bonin M and Sutherland LC: Expression of RBM5-related factors in primary breast tissue. J Cell Biochem 100: 1440-1458, 2007.

49. Zabarovsky ER, Lerman MI and Minna JD: Tumor suppressor genes on chromosome $3 p$ involved in the pathogenesis of lung and other cancers. Oncogene 21: 6915-6935, 2002.

50. Graveley BR: Alternative splicing: Increasing diversity in the proteomic world. Trends Genet 17: 100-107, 2001

51. Nissim-Rafinia M and Kerem B: Splicing regulation as a potential genetic modifier. Trends Genet 18: 123-127, 2002.

52. Wang Z, Lo HS, Yang H, Gere S, Hu Y, Buetow KH and Lee MP: Computational analysis and experimental validation of tumor-associated alternative RNA splicing in human cancer. Cancer Res 63: 655-657, 2003.

53. Zhou Z, Licklider LJ, Gygi SP and Reed R: Comprehensive proteomic analysis of the human spliceosome. Nature 419: $182-185,2002$
54. Jin W, Niu Z, Xu D and Li X: RBM5 promotes exon 4 skipping of AID pre-mRNA by competing with the binding of U2AF65 to the polypyrimidine tract. FEBS Lett 586: 3852-3857, 2012.

55. U.S. Department of Health and Human Services: Smoking, Tobacco, and Cancer Program (1985-1989 Status Report). Public Health Service, USA, 1990.

56. Hecht SS: Cigarette smoking: Cancer risks, carcinogens, and mechanisms. Langenbecks Arch Surg 391: 603-613, 2006.

57. Harvey RG: Polycyclic aromatic hydrocarbons. In: Chemistry and Carcinogenicity. Cambridge University Press, Cambridge, 396, 1991.

58. Beland FA, Cain LG, Felton JS, et al: Chemical Carcinogenesis and Mutagenesis I. Springer-Verlag: 33-572, 1990.

59. Bartsch H: DNA adducts in human carcinogenesis: Etiological relevance and structure-activity relationship. Mutat Res 340: 67-79, 1996.

60. Mass MJ, Jeffers AJ, Ross JA, Nelson G, Galati AJ, Stoner GD and Nesnow S: Ki-ras oncogene mutations in tumors and DNA adducts formed by benz[j]aceanthrylene and benzo[a]pyrene in the lungs of strain A/J mice. Mol Carcinog 8: 186-192, 1993.

61. Venkatachalam S, Denissenko MF, Alvi N and Wani AA: Rapid activation of apoptosis in human promyelocytic leukemic cells by (+/-)-anti-benzo[a]pyrene diol epoxide induced DNA damage. Biochem Biophys Res Commun 197: 722-729, 1993.

62. Denissenko MF, Pao A, Tang M and Pfeifer GP: Preferential formation of benzo[a]pyrene adducts at lung cancer mutational hotspots in P53. Science 274: 430-432, 1996.

63. Wistuba II, Lam S, Behrens C, Virmani AK, Fong KM, LeRiche J, Samet JM, Srivastava S, Minna JD and Gazdar AF: Molecular damage in the bronchial epithelium of current and former smokers. J Natl Cancer Inst 89: 1366-1373, 1997.

64. Jamsai D, Watkins DN, O'Connor AE, Merriner DJ, Gursoy S, Bird AD, Kumar B, Miller A, Cole TJ, Jenkins BJ, et al: In vivo evidence that RBM5 is a tumour suppressor in the lung. Sci Rep 7: 16323, 2017.

65. Prabhu VV and Devaraj N: Regulating RNA binding Motif 5 gene expression-a novel therapeutic target for lung cancer. J Environ Pathol Toxicol Oncol 36: 99-105, 2017.

66. Canoz O, Ozkan M, Arsav V, Er O, Coskun HS, Soyuer S and Altinbas M: The role of c-erbB-2 expression on the survival of patients with small-cell lung cancer. Lung 184: 267-272, 2006.

67. Hirsch FR, Franklin WA, Veve R, Varella-Garcia $M$ and Bunn PA Jr: HER2/neu expression in malignant lung tumors. Semin Oncol 29: 51-58, 2002

68. Bae NC, Chae MH, Lee MH, Kim KM, Lee EB, Kim CH, Park TI, Han SB, Jheon S, Jung TH and Park JY: EGFR, ERBB2, and KRAS mutations in Korean non-small cell lung cancer patients. Cancer Genet Cytogenet 173: 107-113, 2007.

69. Buttitta F, Barassi F, Fresu G, Felicioni L, Chella A, Paolizzi D, Lattanzio G, Salvatore S, Camplese PP, Rosini S, et al: Mutational analysis of the HER2 gene in lung tumors from Caucasian patients: Mutations are mainly present in adenocarcinomas with bronchioloalveolar features. Int J Cancer 119: 2586-2591, 2006.

70. Hao YQ, Su ZZ, Lv XJ, Li P, Gao P, Wang C, Bai Y and Zhang J: RNA-binding motif protein 5 negatively regulates the activity of Wnt/ $\beta$-catenin signaling in cigarette smoke-induced alveolar epithelial injury. Oncol Rep 33: 2438-2444, 2015.

71. Lerman MI and Minna JD: The 630-kb lung cancer homozygous deletion region on human chromosome 3 p21.3: Identification and evaluation of the resident candidate tumor suppressor genes. The International Lung Cancer Chromosome 3p21.3 Tumor Suppressor Gene Consortium. Cancer Res 60: 6116-6133, 2000.

72. Edamatsu H, Kaziro Y and Itoh H: LUCA15, a putative tumour suppressor gene encoding an RNA-binding nuclear protein, is down-regulated in ras-transformed Rat-1 cells. Genes Cells 5: 849-858, 2000.

73. Welling DB, Lasak JM, Akhmametyeva E, Ghaheri B and Chang LS: cDNA microarray analysis of vestibular schwannomas. Otol Neurotol 23: 736-748, 2002.

74. Zhao L, Li R, Shao C, Li P, Liu J and Wang K: 3p21.3 tumor suppressor gene RBM5 inhibits growth of human prostate cancer PC-3 cells through apoptosis. World J Surg Oncol 10: 247, 2012.

75. Kim YS, Hwan JD, Bae S, Bae DH and Shick WA: Identification of differentially expressed genes using an annealing control primer system in stage III serous ovarian carcinoma. BMC Cancer 10: 576, 2010

76. Peng J, Valeshabad AK, Li Q and Wang Y: Differential expression of RBM5 and KRAS in pancreatic ductal adenocarcinoma and their association with clinicopathological features. Oncol Lett 5: 1000-1004, 2013 
77. Oh JJ, Taschereau EO, Koegel AK, Ginther CL, Rotow JK, Isfahani KZ and Slamon DJ: RBM5/H37 tumor suppressor, located at the lung cancer hot spot $3 \mathrm{p} 21.3$, alters expression of genes involved in metastasis. Lung Cancer 70: 253-262, 2010.

78. Toyooka S, Maruyama R, Toyooka KO, McLerran D, Feng Z, Fukuyama Y, Virmani AK, Zochbauer-Muller S, Tsukuda K, Sugio K, et al: Smoke exposure, histologic type and geography-related differences in the methylation profiles of non-small cell lung cancer. Int J Cancer 103: 153-160, 2003.

79. Bechara EG, Sebestyén E, Bernardis I, Eyras E and Valcárcel J: RBM5, 6, and 10 differentially regulate NUMB alternative splicing to control cancer cell proliferation. Mol Cell 52: 720-733, 2013.

80. Wistuba II, Behrens C, Virmani AK, Mele G, Milchgrub S, Girard L, Fondon JW III, Garner HR, McKay B, Latif F, et al: High resolution chromosome $3 p$ allelotyping of human lung cancer and preneoplastic/preinvasive bronchial epithelium reveals multiple, discontinuous sites of $3 p$ allele loss and three regions of frequent breakpoints. Cancer Res 60: 1949-1960, 2000.

81. Liang H, Zhang J, Shao C, Zhao L, Xu W, Sutherland LC and Wang K: Differential expression of RBM5, EGFR and KRAS mRNA and protein in non-small cell lung cancer tissues. J Exp Clin Cancer Res 31: 36, 2012.

82. Oh JJ, West AR, Fishbein MC and Slamon DJ: A candidate tumor suppressor gene, H37, from the human lung cancer tumor suppressor locus 3p21.3. Cancer Res 62: 3207-3213, 2002.

83. ter Elst A, Hiemstra BE, van der Vlies P, Kamminga W, van der Veen AY, Davelaar I, Terpstra P, te Meerman GJ, Gerbens F, Kok K, et al: Functional analysis of lung tumor suppressor activity at 3p21.3. Genes Chromosomes Cancer 45: 1077-1093, 2006.
84. Ji L and Roth JA: Tumor suppressor FUS1 signaling pathway. J Thorac Oncol 3: 327-330, 2008.

85. Agathanggelou A, Bièche I, Ahmed-Choudhury J, Nicke B, Dammann R, Baksh S, Gao B, Minna JD, Downward J, Maher ER and Latif F: Identification of novel gene expression targets for the Ras association domain family 1 (RASSF1A) tumor suppressor gene in non-small cell lung cancer and neuroblastoma. Cancer Res 63: 5344-5351, 2003.

86. Castro-Rivera E, Ran S, Thorpe P and Minna JD: Semaphorin 3B (SEMA3B) induces apoptosis in lung and breast cancer, whereas VEGF165 antagonizes this effect. Proc Natl Acad Sci USA 101: 11432-11437, 2004

87. Carboni GL, Gao B, Nishizaki M, Xu K, Minna JD, Roth JA and Ji L: CACNA2D2-mediated apoptosis in NSCLC cells is associated with alterations of the intracellular calcium signaling and disruption of mitochondria membrane integrity. Oncogene 22: 615-626, 2003.

88. Qiu TH, Chandramouli GV, Hunter KW, Alkharouf NW, Green JE and Liu ET: Global expression profiling identifies signatures of tumor virulence in MMTV-PyMT-transgenic mice: Correlation to human disease. Cancer Res 64: 5973-5981, 2004.

89. Ramaswamy S, Ross KN, Lander ES and Golub TR: A molecular signature of metastasis in primary solid tumors. Nat Genet 33: 49-54, 2003.

90. Loiselle JJ, Roy JG and Sutherland LC: RBM5 reduces small cell lung cancer growth, increases cisplatin sensitivity and regulates key transformation-associated pathways. Heliyon 2: e00204, 2016.

91. Loiselle JJ, Roy JG and Sutherland LC: RBM10 promotes transformation-associated processes in small cell lung cancer and is directly regulated by RBM5. PLoS One 12: e0180258, 2017. 